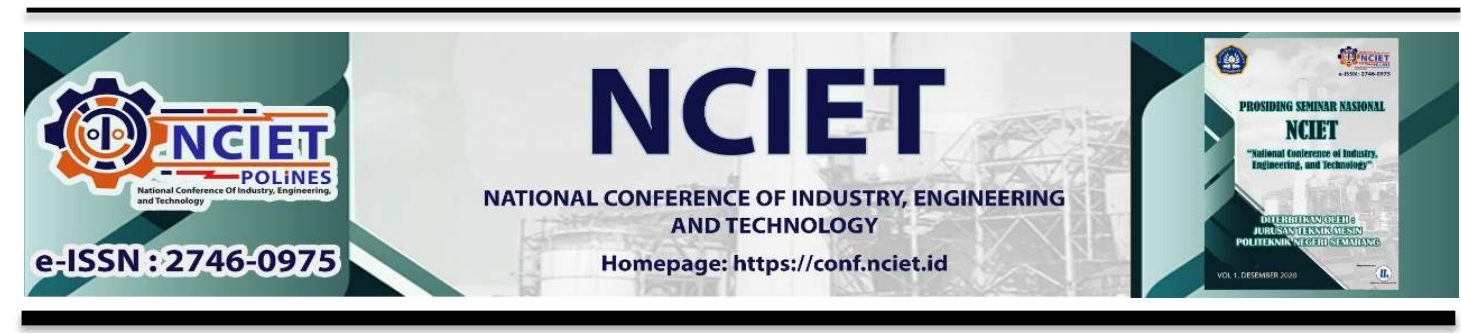

Prosiding Seminar Nasional NCIET Vol.1 (2020) B350-B358

$1^{\text {st }}$ National Conference of Industry, Engineering and Technology 2020,

Semarang, Indonesia.

\title{
RANCANG BANGUN TURBIN AIR ALIRAN PIPA DENGAN JUMLAH SUDU 3, 4 DAN 5
}

\section{Bono*, Gatot Suwoto, Hikmah Nur Aini, M. Fadel Albasith, M. Hasan Fikri, Ulva Anandya}

Jurusan Teknik Mesin, Politeknik Negeri Semarang

Jl. Prof H. Soedarto, SH, Tembalang, Semarang, 50275

*E-mail: onobono61@yahoo.co.id

\begin{abstract}
Abstrak
Tujuan utama penelitian ini adalah mengkaji secara eksperimental kinerja turbin poros vertikal yang dipasang pada aliran air di daam pipa, dengan jumlah sudu tiga, empat, dan lima. Model turbin tersebut diuji pada saluran uji yang terdiri dari pompa untuk membangkitkan potensi air, alat uji turbin dan alat ukur. Parameter yang diukur dalam pengujian adalah, perbedaan tinggi air pada orifice $(\mathrm{h})$, perbedaan tekanan air pada sisi masuk turbin dan sisi keluar turbin $(\Delta \mathrm{P})$, kecepatan putar (n), tegangan keluaran generator (V), arus listrik yang mengalir ke beban (I), dan temperatur air (T). Parameter yang ditentukan dan merupakan variabel penelitian ini adalah jumlah sudu pada masing masing runner turbin. Daya generator yangdihasilkan oleh turbin dengan jumlah sudu 3, 4 dan 5 , padadebit $0,007 \mathrm{~m}^{3} / \mathrm{s}$, head $4 \mathrm{~m}$ masing- masing adalah5,875 W pada putaran $403,6 \mathrm{rpm} ; 11,438 \mathrm{~W}$ pada putaran $484,9 \mathrm{rpm}$; serta $12,825 \mathrm{~W}$ pada putaran563 rpm.Sedangkan debit $0,006 \mathrm{~m}^{3} / \mathrm{s}$ head $3 \mathrm{~m}$ masing-masing adalah4,042 $\mathrm{W}$ pada putaran 340,6 rpm; 5,29 W pada putaran 372,9 rpm serta 7,2 W pada putaran 457,7 rpm. Turbin sudu 5 memiliki daya generator yang lebih besar dibandingkan dengan turbin sudu 4 dan turbin sudu 3 pada debit $0,007 \mathrm{~m}^{3} / \mathrm{s}$ maupun debit $0,006 \mathrm{~m}^{3} / \mathrm{s}$
\end{abstract}

Kata Kunci: Turbin vertical; aliran pipa; jumlah; daya generator

\section{PENDAHULUAN}

Salah satu potensi air yang belum dimanfaatkan secara maksimal adalah potensi yang berada pada saluran distribusi air dari mata air ke rumah-rumah warga, juga pada saluran yang ada di industri. Mengubah energi dari air minum yang mengalir di pipa menjadi listrik menjadi arah baru perkembangan teknologi inovatif di bidang teknik. Saat ini, banyak perangkat berbeda yang dirancang untuk tujuan ini tersedia di pasaran. Ada turbin air, terintegrasi dengan generator, ditempatkan di dalam pipa. Sehubungan dengan kondisi tersebut di atas, maka perlu diupayakan pemanfaatan potensi aliran air di dalam pipa sebagai energi penggerak turbin untuk menghasilkan energi listrik. Pembangkit listrik dengan memanfaatkan aliran air di dalam pipa masih terbatas dan sangat jarang ditemui, kondisi ini 
menarik perhatian kami untuk melakukan penelitian tentang pembangkit listrik dengan memanfaatkan aliran air di didalam pipa sebagai penggerak turbinnya. Turbin air yang akan diteliti adalah turbin yang dipasang di dalam pipa dengan posisi tegak, dengan bilah sudu terbuat dari plat besi dan jumlah sudunya bervariasi.

Penelitian ini bertujuan untuk memanfaatkan energi yang dihasilkan oleh aliran air di dalam pipa, dengan cara membuat turbin air yang diintegrasikan ke dalam pipa dengan variasi jumlah sudu 3, 4 dan 5, serta menguji kinerja turbin air tersebut.

Chen, Jian. (2013), melakukan penelitian tentang Turbin Air Poros Vertikal Pada Aliran Pipa dengan dua jenis rotor sudu, yaitu rotor sudu solid dan rotor sudu berongga, Hasil penelitian menunjukkan bahwa rotor dengan struktur berongga dapat menghasilkan daya maksimum dibandingkan dengan jenis rotor sumbu vertikal lainnya. selama uji eksperimen satu tahun dan simulasi CFD, daya keluaran meningkat secara signifikan dari nol hingga $88,2 \mathrm{~W}$

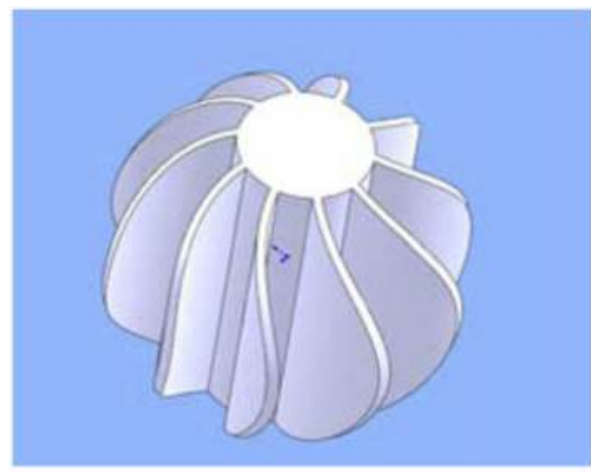

a

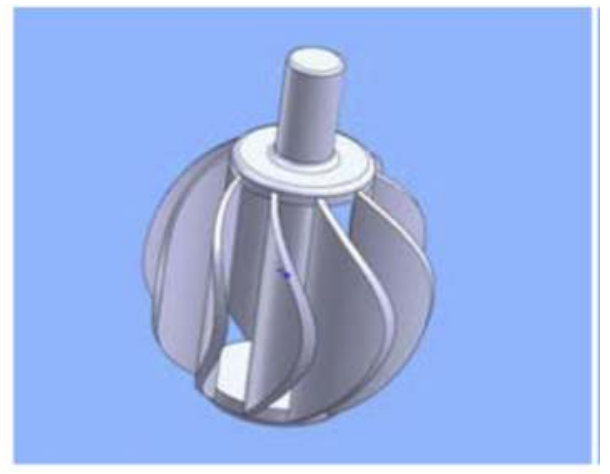

b

Gambar 1. rotor sudu yag diuji, (a) rotor solid, (b) rotor berongga

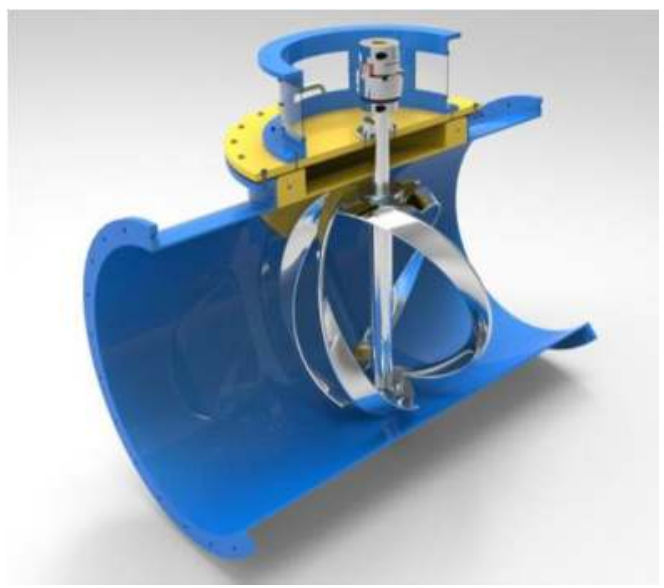

Gambar 2. rotor sudu yag diuji, (a) rotor solid, (b) rotor berongga (Sumber: In-pipe Water Power Generation from Spherical Turbine, 2017) 
Roshan Varghese Rajan (2016), merancang sistem pembangkit pico-hidro sebagai sumber energi alternatif dengan mengkonsumsi air dari tangki air bangunan tempat tinggal. Ini bisa menjadi bentuk energi yang andal dan ramah lingkungan, yang dapat dihasilkan untuk mengembangkan pembangkit listrik tenaga air skala kecil. Sistem pico hydro memanfaatkan energi air yang disimpan di reservoir air. Air yang disimpan di bak air bangunan tempat tinggal dengan ketinggian minimal $3 \mathrm{~m}$ dapat digunakan untuk pembangkit listrik pico.

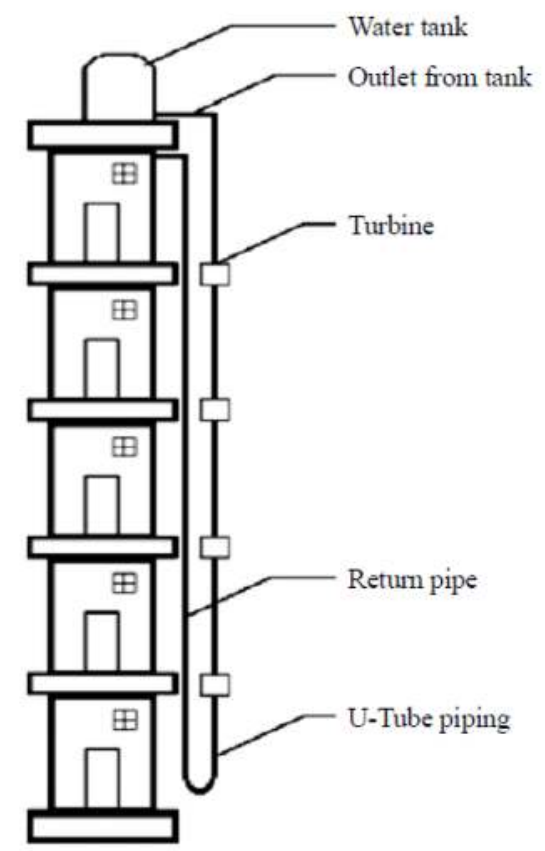

Gambar 3. Listrik pico-hydro perumahan

Marco casini (2015), mengelompokkan sistem pembangkit listrik tenaga air pipa menjadi dua desain utama:

1. Sistem internal, di mana runner seluruhnya berada di dalam bagian pipa dan hanya generator yang menonjol dari saluran. Sistem internal (Gambar. 4) memiliki keuntungan dari ukuran yang lebih kompak yang membuatnya lebih cocok, tetapi tidak dibatasi, untuk aplikasi yang lebih kecil. Output daya berkisar dari 5-10 watt, cukup untuk memasok sistem pengukuran atau pemantauan air bertenaga sendiri, hingga $100 \mathrm{~kW}$ untuk aplikasi yang lebih intensif. 


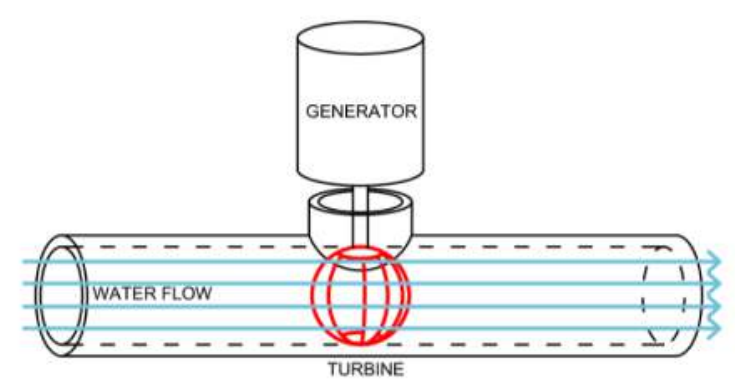

Gambar 4. Sistem internal

2. Sistem eksternal, di mana runner berada dalam saluran sekunder yang melewati saluran utama. Sistem eksternal (Gambar. 5) tidak terlalu bergantung pada ukuran pipa karena runner tertutup dalam saluran khusus, dan memungkinkan fleksibilitas yang lebih besar. Kelemahan utama mereka adalah kebutuhan kubah yang lebih besar untuk menampung turbin dan perakitan generator,

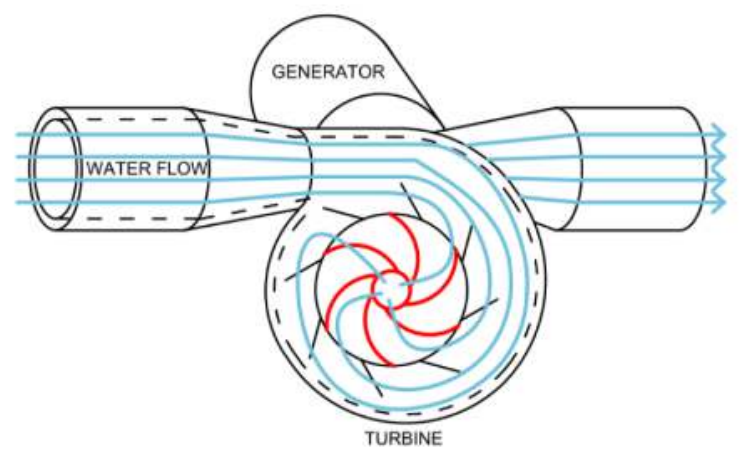

Gambar 5. Sistem eksternal

\section{METODE PENELITIAN}

Penelitian ini diawali dengan membuat turbin air poros vertikal, dengan runner turbin diletakan di dalam pipa berdiaeter 4 inchi. Runner turbin dibuat sebanyak 3 buah,. dengan masing masing runner memiliki sudu sebanyak 3, 4, dan 5 bilah sudu, bilah sudu terbuat dari plat setebal $2 \mathrm{~mm}$, seperti ter;ihat pada Gambar 6

Parameter yang diukur dalam pengujian adalah debit aliran (Q), putaran turbin (n) dan tinggi tekan air sebelum turbin $\left(\mathrm{P}_{1}\right)$, tinggi tekan air setelah turbin $\left(\mathrm{P}_{2}\right)$, serta tegangan dan arus listrik yang keluaran dari generator. Beban pada generator divariasikan dan setiap variasi dilakukan pencatatan terhadap parameter-parameter diatas. Alat ukur yang digunakan pada saat pengujian adalah manometer, tachometer, Volt meter, Ampere meter, orifice meter. 

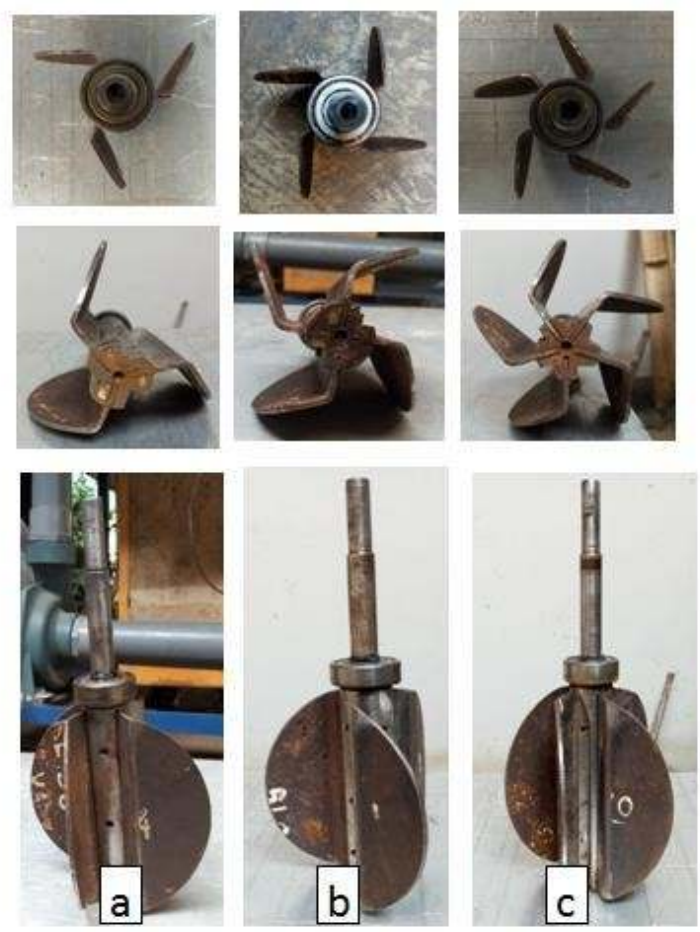

Gambar 6. Runner Turbin Air Poros Vertikal

(a) runner 3 sudu (b) runner 4 sudu (c) runner 5 sudu

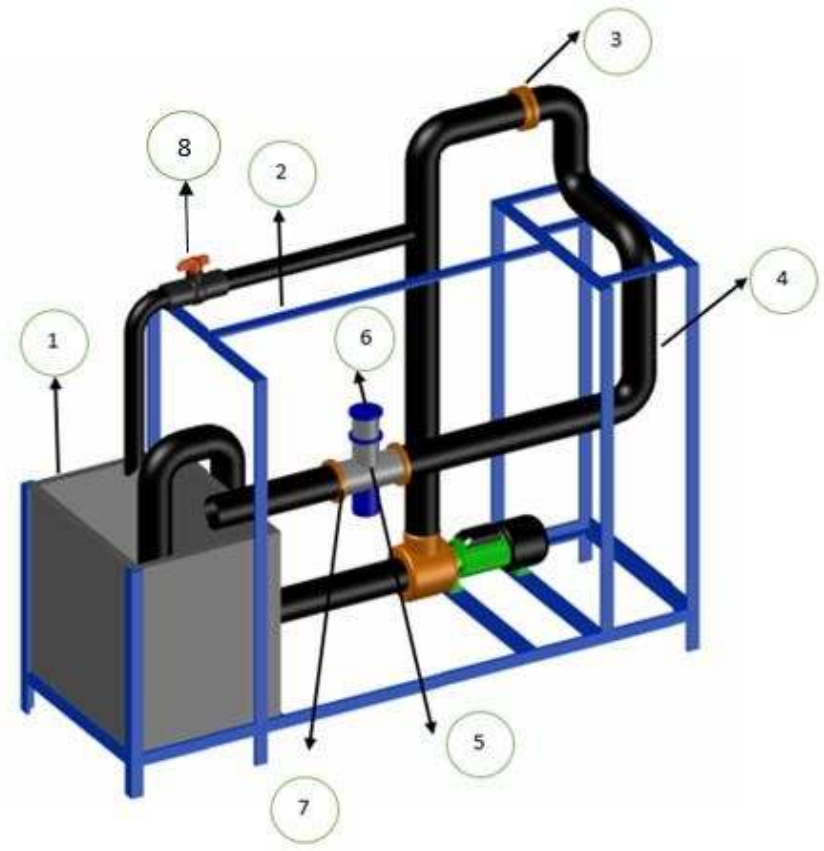

Gambar 7.:Instalasi pengujian. 
(1). Bak penampung air, (2). Plat baja profil, (3). orifice, (4). Pipa PVC, (5). Rumah turbin air, (6). Flange penutup, (7). Flange, (8). Katup bypass

\section{HASIL DAN PEMBAHASAN}

Piringan putar (runner) turbin air yang digunakan dalam penelitian ini mempunyai diameter 91,5 mm, dengan jumlah sudu masing masing runner sebanyak 3, 4, dan 5 bilah sudu. Pengujian dilakukan pada debit air 6 liter/detik, dan 7 liter/detik. Grafik hubungan antara daya generator terhadap putaran turbin pada berbagai jumlah bilah sudu, dapat dilihat seperti pada gambar 8 dan gambar 9, sebagai berikut.

Dari hasil pengujian serta perhitungan ketiga turbin dengan variasi jumlah sudu 3, 4, dan 5 pada $\mathrm{Q}=0,007 \mathrm{~m}^{3} / \mathrm{s}$ ditampilkan hasil karakteristik daya generator tehadap putaran turbin dalam bentuk grafik pada Gambar 8

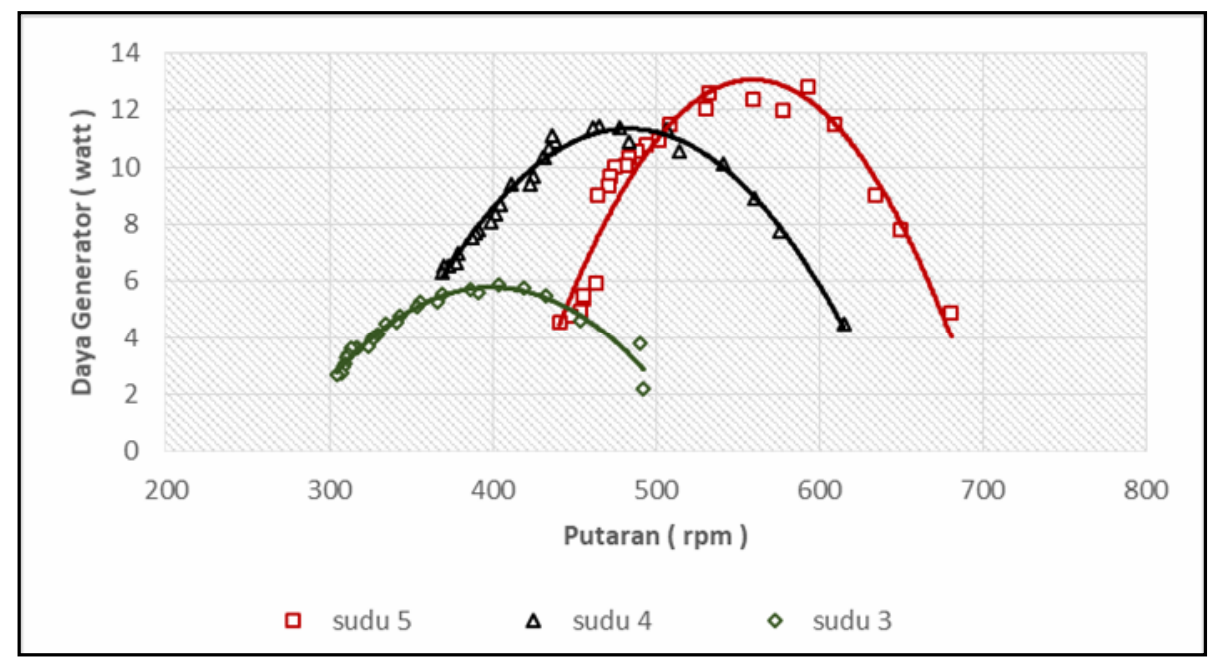

Gambar 8. Grafik hubungan Daya Generator dengan putaran pada $\mathrm{Q}=0,007 \mathrm{~m}^{3} / \mathrm{s}$

Gambar 8 merupakan karaktersitik daya generator terhadap putaran turbin. Turbin air 3 sudu memiliki daya generator terbesar 5,875 watt pada putaran turbin 403,6 rpm. Turbin air 4 sudu memiliki daya generator terbesar 11,438 watt pada putaran turbin 464,9 rpm. Turbin air 5 sudu memiliki daya generator terbesar 12,825 watt pada putaran turbin $593 \mathrm{rpm}$. Dari ketiga turbin yang telah diuji, dapat dilihat bahwa semakin besar putaran maka daya generator semakin besar pula hingga mencapai titik puncak lalu akan menurun seiring bertambahnya putaran. 
Jika daya generator pada masing masing jumlah sudu dibandingkan satu dengan lainnya, maka antara sudu 5 dengan sudu 4 terjadi perbedaaan sebesar 1,387 W, Perubahan jumlah sudu dari 4 buah menjadi 5 buah memberikan peningkatan daya sebesar 12,13\%, , antara sudu 5 dengan sudu 3 terdapat perbedaan sebesar 6,95 W, Perubahan jumlah sudu dari 3 buah menjadi 5 buah memberikan peningkatan daya sebesar 118,3\%, sedangkan antara sudu 4 dengan sudu 3 terdapat perbedaan 5,563 W, Perubahan jumlah sudu dari 3 buah menjadi 5 buah memberikan peningkatan daya sebesar $94,67 \%$,

Dari hasil pengujian serta perhitungan ketiga turbin dengan variasi jumlah sudu 3, 4, dan 5 pada $\mathrm{Q}=0,006 \mathrm{~m}^{3} / \mathrm{s}$ ditampilkan hasil karakteristik daya generator tehadap putaran turbin dalam bentuk grafik pada Gambar 9

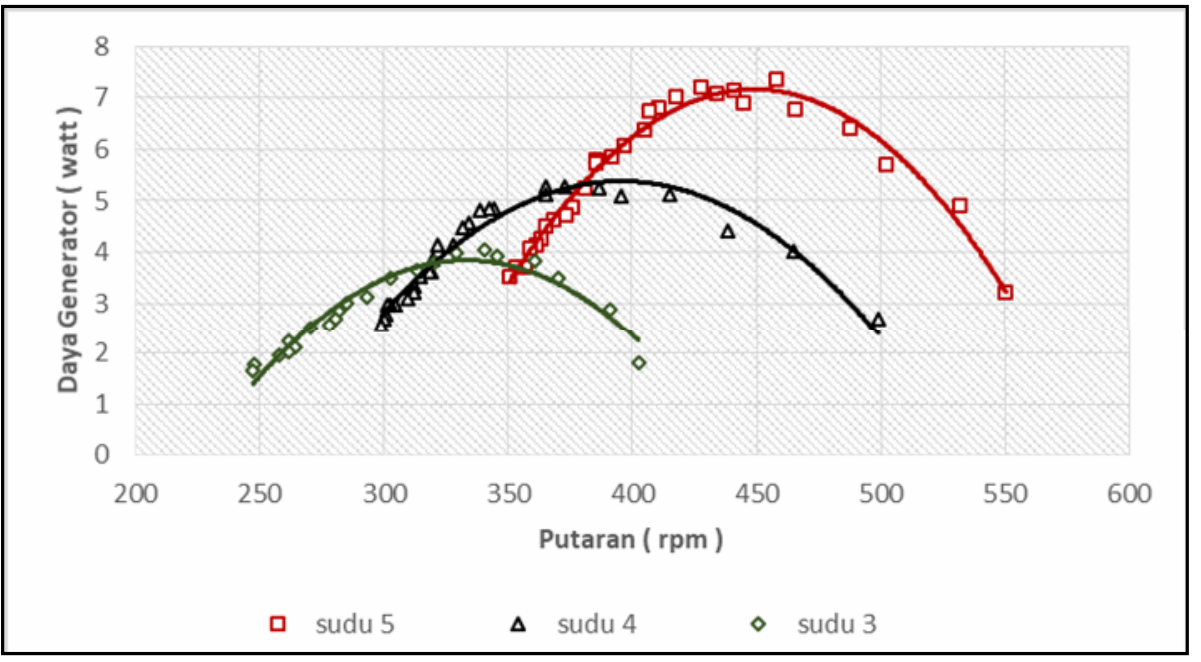

Gambar 9. Grafik hubungan Daya Generator dengan putaran pada $\mathrm{Q}=0,006 \mathrm{~m}^{3} / \mathrm{s}$

Gambar 9 merupakan karaktersitik daya generator terhadap putaran turbin. Turbin air 3 sudu memiliki daya generator terbesar 4,042 watt pada putaran turbin 340,6 rpm. Turbin air 4 sudu memiliki daya generator terbesar 5,29 watt pada putaran turbin 372,9 rpm. Turbin air 5 sudu memiliki daya generator terbesar 7,2 watt pada putaran turbin 427,7 rpm. Dari ketiga turbin yang telah diuji dapat dilihat bahwa semakin besar putaran maka daya generator semakin besar pula hingga mencapai titik jenuh lalu akan menurun seiring bertambahnya putaran.

Jika daya generator pada masing masing jumlah sudu dibandingkan satu dengan lainnya, maka antara sudu 5 dengan sudu 4 terjadi perbedaaan sebesar 1,91 W, Perubahan jumlah sudu dari 4 buah menjadi 5 buah memberikan peningkatan daya sebesar $36,1 \%$, antara sudu 
5 dengan sudu 3 terdapat perbedaan sebesar 3,158 W, Perubahan jumlah sudu dari 3 buah menjadi 5 buah memberikan peningkatan daya sebesar $78,13 \%$, sedangkan antara sudu 4 dengan sudu 3 terdapat perbedaan 1,248 W, Perubahan jumlah sudu dari 3 buah menjadi 5 buah memberikan peningkatan daya sebesar $30,87 \%$,

\section{KESIMPULAN}

Pengujian turbin air poros vertikal pada aliran pipa yang telah dilakukan menghasilkan data yang diolah sehingga diperoleh kesimpulan sebagai berikut :

1. Pada debit $0,007 \mathrm{~m}^{3} / \mathrm{s}$ dengan head $4 \mathrm{~m}$, daya generator yang dihsikan dari ketiga dengan jumlah sudu 3, 4 dan 5 masing-masing adalah 5,875 Watt pada putaran 403,6 rpm; 11,438 Watt pada putaran 484,9 rpm; dan 12,825 Watt pada putaran $563 \mathrm{rpm}$.

2. Terjadi peningkatan daya sebesar $12,13 \%$, untuk perubahan jumlah sudu dari 4 buah menjadi 5 buah

3. Terjadi peningkatan daya sebesar $118,3 \%$, untuk perubahan jumlah sudu dari 3 buah menjadi 5 buah

4. Terjadi peningkatan daya sebesar $94,67 \%$, untuk perubahan jumlah sudu dari 3 buah menjadi 5 buah

5. daya generator yang dihasilkan oleh turbin dengan jumlah sudu 3, 4 dan 5 untuk debit $0,006 \mathrm{~m}^{3} / \mathrm{s}$ head $3 \mathrm{~m}$ masing masing adalah 4,042 Watt pada putaran 340,6 rpm; 5,29 Watt pada putaran 372,9 rpm; dan 7,2 Watt pada putaran 457,7 rpm.

6. Terjadi peningkatan daya sebesar $36,1 \%$, untuk perubahan jumlah sudu dari 4 buah menjadi 5 buah

7. Terjadi peningkatan daya sebesar $78,13 \%$, untuk perubahan jumlah sudu dari 3 buah menjadi 5 buah

8. Terjadi peningkatan daya sebesar $30,87 \%$, untuk perubahan jumlah sudu dari 3 buah menjadi 5 buah

\section{DAFTAR PUSTAKA}

Chen, Jian. (2013). A Novel Vertical Axis Water Turbine for Power Generation from Water Pipelines, Energy 54 184-193

Marco Casini (2015), Harvesting energy from in-pipe hydro systems at urban and building scale, International Journal of Smart Grid and Clean Energy, vol. 4, no. 4,

Prakoso, Rangga. 2018. Potensi Energi Air di Indonesia. https://www.beritasatu.com/ekonomi/488923/indonesia-punya-potensi-energi- air- 
75000-mw. Diakses 23 Mei 2019.

Roshan Varghese Rajan, K. Suresh, Sanu Ipe, Arjun K. Kurup And Aby M. George, (2016), Pico-Hydro Electric Power Generation From Residential Water Tank, Int. J. Chem. Sci.: 14(1), 2016, 421-426 ISSN 0972-768X

Vasu Dixit, Nirav Patel, Rhishabh Jadhav, (2017), In-pipe Water Power Generation from Spherical Turbine, International Journal of Scientific \& Engineering Research, Volume 8, Issue 4, ISSN 2229-5518 